\title{
Inhalation powder and oral salbutamol combination
}

\author{
K P DAWSON, C E M UNTER, S DEO, AND D M FERGUSSON \\ Department of Paediatrics, Christchurch Clinical School of Medicine, Christchurch Hospital, \\ New Zealand
}

SUMmaRY Fifty six children with chronic asthma were treated with the inhaled dry powder of salbutamol or the combination of inhaled and oral salbutamol. Over three months the combination provided a significantly greater sustained symptomatic relief from asthma. Side effects were minimal and did not result in any withdrawals from the study.

We have previously shown the superior characterisics of combining tablets and inhaled dry powder of salbutamol in children with asthma on a short term basis. The combination had a rapid onset of effect and a sustained period of action. This initial study revealed no untoward side effects in the short term. ${ }^{1}$

To determine whether the combination treatment was superior to inhalation treatment alone in the symptomatic control of asthma over a three month period, we have performed a double blind placebo controlled trial. Specific attention was paid to the possibility of troublesome side effects during the study.

\section{Patients and methods}

Fifty eight children with moderately severe chronic asthma (grade C) ${ }^{2}$ entered the study, and fifty six completed an assessment of three months. This group consisted of 38 boys and 18 girls. Their ages ranged from 4 to 12 years, with a mean age of $7 \cdot 8$ years.

A double blind placebo design was used, and the patients were assigned to one of two treatments by means of a randomisation code. The two groups did not differ significantly in terms of age range, sex difference, or duration and severity of asthma. The treatments were:

(1) Salbutamol 400 mcg capsules through a rotahaler given at 0800,1400 , and $2000 \mathrm{~h}$, and salbutamol tablets $4 \mathrm{mg}$ taken after the inhalation.

(2) As treatment (1), except that the salbutamol tablets were replaced by identical looking placebo tablets containing lactose.

Both groups were permitted extra inhalational treatment in response to symptoms.
Before inclusion in the study each child's ability to inhale correctly from a rotahaler was confirmed.

For each of the three months that formed the study period a number of measures of the child's therapeutic response were obtained from a maternal daily diary record of symptoms. For each month the number of days on which each symptom was present-that is, symptom days-was recorded for the symptoms of night cough, night wheeze, day wheeze, day cough, and restriction of activity. A measure of the child's global response to treatment during each month was obtained by summing the number of symptom days for each of the above categories.

Additionally, the number of extra inhaled capsules, sympathomimetic nebuliser treatments, and admissions to hospital required were recorded throughout the three months. Recording of side effects and specific note of excitability or behavioural change was made. The children were reviewed monthly at an outpatient clinic where daily diary records were checked and any additional side effects recorded.

\section{Results}

Table 1 shows the relation between the mean symptom day scores over the three months and the treatment group to which the children had been assigned (powder and active tablet versus powder and placebo tablet). The results were analysed using two way analysis of variance in which the mean scores were contrasted over the two treatment groups (active; placebo) and the three months. The treatment factor was treated as a fixed factor and the time of measurement factor as a repeated measures factor. The results in Table 1 show the significant 
levels of the treatment factor only for each comparison. Table 1 shows that for all comparisons there was a tendency for the group of children treated with the active tablet to have fewer symptom days. This trend was significant for the measures of night cough, day cough, and total symptom scores. This suggests that treatment with the active tablet produced greater symptomatic relief of symptoms of asthma and particularly cough. This relief seemed to be sustained throughout the three months.

Table 2 compares the two groups for a number of measures of the need for additional treatment. These measures include the mean number of nebuliser treatments needed by the child during the three months, the mean number of additional capsules used by the child over and above the basic regimen of three each day, and the proportion of children who were admitted to hospital as a result of acute asthma. Table 2 suggests the presence of dramatic differences in the outcomes of the two treatments, with children receiving the active tablet requiring only $40 \%$ of the repeat nebulisations and half as

Table 1 Mean symptom days for subjects assigned to the active and placebo treatments

\begin{tabular}{|c|c|c|c|c|c|}
\hline \multirow[t]{2}{*}{ Measure } & \multirow[t]{2}{*}{ Treatment } & \multicolumn{3}{|c|}{$\begin{array}{l}\text { Time of measurement } \\
\text { (months) }\end{array}$} & \multirow[t]{2}{*}{$p$ Value } \\
\hline & & $l$ & 2 & 3 & \\
\hline \multirow[t]{2}{*}{ Night whecze } & Active & 1.89 & 0.75 & 0.82 & \multirow{2}{*}{ NS } \\
\hline & Placebo & $2 \cdot 19$ & 1.78 & $1 \cdot 41$ & \\
\hline \multirow[t]{2}{*}{ Night cough } & Active & 2.53 & $1 \cdot 21$ & 1.89 & \multirow{2}{*}{$<0.05$} \\
\hline & Placebo & 4.52 & 2.89 & $2 \cdot 85$ & \\
\hline \multirow[t]{2}{*}{ Day wheeze } & Active & 1.54 & 0.54 & (). 61 & \multirow{2}{*}{ NS } \\
\hline & Placebo & 1.52 & 1.37 & $(0.81$ & \\
\hline \multirow[t]{2}{*}{ Day cough } & Active & $1 \cdot 18$ & $(0.75$ & 1.29 & \multirow{2}{*}{$<0.05$} \\
\hline & Placebo & $2 \cdot 15$ & $2 \cdot(14$ & $2 \cdot 26$ & \\
\hline \multirow[t]{2}{*}{ Restricted activity } & Active & 1.32 & 0.86 & 1.21 & \multirow{2}{*}{ NS } \\
\hline & Placebo & 0.93 & 1.70 & $1 \cdot 30$ & \\
\hline \multirow[t]{2}{*}{ Total symptom days } & Active & $8 \cdot 46$ & $4 \cdot 11$ & $5 \cdot 82$ & \multirow{2}{*}{$<0.05$} \\
\hline & Placebo & $11 \cdot 31$ & 9.78 & 8.63 & \\
\hline
\end{tabular}

$\mathrm{NS}=$ Not significant.

Table 2 Use of additional treatment during the three months in the active and placebo treatment groups

\begin{tabular}{llcc}
\hline Treatment & \multicolumn{2}{l}{ Treatment group } & p Value \\
\cline { 2 - 3 } & Active & Placebo & \\
\hline $\begin{array}{l}\text { Mean No of nebulisers required } \\
\begin{array}{l}\text { Mean No of capsules taken on top } \\
\text { of basic } 3 \text { each day }\end{array}\end{array}$ & 1.89 & 4.48 & $\mathrm{NS}$ \\
$\begin{array}{l}\% \text { Admitted to hospital with } \\
\text { acute asthma }\end{array}$ & 17.43 & 36.59 & $<0.1$ \\
\hline NS= Not significant. & $28.6 \%$ & $4(0.7 \%$ & $\mathrm{NS}$ \\
\hline
\end{tabular}

many additional inhalations and having about $60 \%$ of the rate of admission to hospital when compared with the group assigned to placebo. Because of the fairly small numbers of subjects studied, however, these differences failed to reach significance, although the number of additional inhalations taken was of marginal significance $(p<0 \cdot 1)$.

Collectively, these findings provide a fairly convincing case for the view that the active tablet provided greater therapeutic benefit than the placebo tablet: children assigned to this regimen showed a consistent tendency to have fewer symptom days on all measures and were less prone to require additional treatment.

Of the original 58 children randomised to two groups, one child from each was eliminated because of failure to keep diary records. Of the remaining 56 children, there were eight reports of side effects, four from each group, although all continued on treatment and completed the three month evaluation.

In the active treatment group three children were regarded as being more active than usual, one for one month and two for all three months of the study. The other child was noted to have tremors for one week, but these abated spontaneously. In the placebo treatment group one child was regarded as overactive and had tremors, while two had headaches and the fourth was reported as lacking energy. These were regarded as minimal features and the children were continued on their regimen.

\section{Discussion}

This study has examined the extent to which giving paediatric patients with asthma treatment with salbutamol tablets in addition to inhalation powder provides greater sustained symptomatic relief from asthma. The results of the study clearly suggest that there are therapeutic benefits from this regimen as children receiving the active tablet had a consistent tendency to have fewer symptom days and required additional treatment less often. These findings are consistent with previous studies, which have shown that under controlled conditions over a short time the combination of powder and tablet provided a treatment with a time/response function that had a rapid onset (due largely to the rapid action of the powder component) and a sustained period of action (due largely to the longer acting effects of the tablet component). The present study shows that such effects do result in a reduction in both symptoms and the need for additional treatment when studied over a fairly prolonged period.

Few side effects were observed during the course of the trial, although it must be borne in mind that 
the number of subjects studied was fairly small. While overactivity was reported as the main problem in the combination group and headache in the group receiving inhalation only, none of the symptoms was severe enough to warrant stopping treatment nor did any family choose to do so unilaterally.

We conclude that this is a useful treatment for children able to inhale from a powder device and swallow tablets and may also provide a good alternative for those who are intolerant of theophyllines. ${ }^{3}$

\section{References}

1 Grimwood K, Fergusson DM, Dawson KP. The combination of salbutamol inhalation powder and tablets in asthma. Arch Dis Child 1983;58:283-5.

2 Williams HE, Phelan PD. In: Respiratory illness in children. Oxford: Blackwell, 1975:116-81.

${ }^{3}$ Loftus BG, Price JF. Treatment of asthma in pre-school children with slow release theophylline. Arch Dis Child 1985;60:770-2.

Correspondence to Dr K P Dawson, Department of Pacdiatrics, Christchurch Hospital, Christchurch, New Zealand.

Received 22 July 1986

Fifty years ago

The blood-sugar in convulsions of infancy and childhood

Margaret B Maclean (Glasgow)-Arch Dis Child 1936;11:247-256

'It has long been recognized that severe convulsive attacks are followed by depletion of the carbohydrate resources of the body.

'Blood sugar estimations were made in a series of children admitted to hospital on account of convulsions, and an attempt was made to follow the changes occurring in the blood-sugar level from the beginning of a convulsion till some hours after it had ceased. The patients were aged from two days to eleven and a half years, and seizures were due to various causes. High blood sugar values occur most frequently in the first three hours after the convulsions, and hypoglycaemic readings were recorded most frequently between the fourth to twelfth hours. A blood sugar level of more than $180 \mathrm{mgm}$ per cent was taken as indicating hyperglycaemia and one of less than $60 \mathrm{mgm}$ per cent as hypoglycaemia.

'Hyperglycaemia occurred most commonly in cases of tuberculous meningitis and hypoglycaemia after intracranial injury in the new born.

'There are two possible explanations for the hypoglycaemia. It may be that violent muscular exertion uses all the available carbohydrate or that the central stimulation, acting as it does on the suprarenals, leads to exhaustion of adrenaline and to a cessation of glycogenolysis. The first suggestion is unlikely as the hypoglycaemia persisted in spite of taking food. To prove the second, adrenaline was injected when the hypoglycaemic stage was reached and there was an immediate response in two children; showing that the tissues are able to form glucose when adrenaline is supplied.'

(This paper raises the possibility that 'in some children hypoglycaemia plays no part in the causation of convulsions but that the upset in carbohydrate metabolism is the result of them'. If fits do persist, or the child remains drowsy for an unusually long time, it may be justifiable to consider that there may be a lack of adrenaline, and instigate investigations and treatment accordingly. NEIL GORDON.) 